\title{
Article \\ Beekeeping in the Desert: Foraging Activities of Honey Bee during Major Honeyflow in a Hot-Arid Ecosystem
}

\author{
Abdulaziz S. Alqarni ${ }^{1, *(\mathbb{D}}$, Javaid Iqbal ${ }^{1, *(\mathbb{D}}$, Hael S. Raweh ${ }^{1}$, Awad M. A. Hassan ${ }^{1,2}$ and Ayman A. Owayss ${ }^{1,3}$ \\ 1 Department of Plant Protection, College of Food and Agriculture Sciences, King Saud University, \\ Riyadh 11451, Saudi Arabia; hraweh@ksu.edu.sa (H.S.R.); awad.univ@gmail.com (A.M.A.H.); \\ aao01@fayoum.edu.eg (A.A.O.) \\ 2 Department of Plant Protection, Faculty of Agriculture, South Valley University, Qena 83523, Egypt \\ 3 Department of Plant Protection, Faculty of Agriculture, Fayoum University, Fayoum 63514, Egypt \\ * Correspondence: alqarni@ksu.edu.sa (A.S.A.); jiqbal@ksu.edu.sa (J.I.)
}

Citation: Alqarni, A.S.; Iqbal, J.; Raweh, H.S.; Hassan, A.M.A.; Owayss, A.A. Beekeeping in the Desert: Foraging Activities of Honey Bee during Major Honeyflow in a Hot-Arid Ecosystem. Appl. Sci. 2021, 11, 9756. https://doi.org/10.3390/ app11209756

Academic Editor: José Alberto Pereira

Received: 13 September 2021

Accepted: 12 October 2021

Published: 19 October 2021

Publisher's Note: MDPI stays neutral with regard to jurisdictional claims in published maps and institutional affiliations.

Copyright: () 2021 by the authors. Licensee MDPI, Basel, Switzerland. This article is an open access article distributed under the terms and conditions of the Creative Commons Attribution (CC BY) license (https:// creativecommons.org/licenses/by/ $4.0 /)$.

\begin{abstract}
This study investigated the outgoing and pollen-gathering foraging activities of Apis mellifera jemenitica $(A M J)$ and Apis mellifera carnica $(A M C)$ under a hot-arid environment in the presence of nectar-rich melliferous Ziziphus nummularia flora. The data revealed the differential effects of weather conditions and Z. nummularia flora on the foraging activities of the studied honey bee subspecies in the Rawdat-Khuraim oasis in central Saudi Arabia. Z. nummularia exhibited two flowering seasons, from June-July (season I) and August-October (season II), with a significantly higher mean flowering density observed during season II ( 404 flowers $/ \mathrm{m}^{2}$ ) than during season I ( 235 flowers $/ \mathrm{m}^{2}$ ). $A M J$ showed significantly higher foraging activities (outgoing and pollen-gathering) than $A M C$ (exotic bees) during all months in each flowering season. The mean outgoing and pollen-gathering foraging rates of $A M J(32.40 \pm 0.67$ and $4.88 \pm 0.40$ workers/colony/min, respectively) were significantly higher than those of $A M C$ (15.93 \pm 1.20 and $2.39 \pm 0.23$ workers/colony/min, respectively) The outgoing and pollen-gathering foraging activities of the two subspecies fluctuated throughout the different times of day. Foraging activities were considerably high at sunrise (SR) and low at noon $(\mathrm{N})$ during both flowering seasons. We also observed seasonal variations in the foraging activities of both bee subspecies. The mean foraging activities (outgoing and pollen-gathering) were slightly higher in season I ( $27.43 \pm 1.21$ and $4.46 \pm 0.45$ workers/colony / min, respectively) than in season II (21.71 \pm 0.86 and $3.02 \pm 0.22$ workers/colony/min, respectively). The thermal window analysis revealed a significant difference between the flight activities (bees exiting and returning to the nest throughout the day) of $A M J$ and $A M C$; $A M J$ had a higher temperature threshold than $A M C$. The outgoing and pollen-gathering foraging activities within each bee subspecies were positively correlated. The present study can help researchers understand the performances of honeybees and the association of their performances with weather and nectar-rich flora conditions.
\end{abstract}

Keywords: arid environment; bee subspecies; flight activity; foraging; flowering season; Ziziphus nummularia; Apis mellifera

\section{Introduction}

Beekeeping in the tropics and subtropics is challenged by shortage of rich nectar floral resources with variations in the dates of honeyflow occurrence [1]. Ziziphus nummularia (Burm. f.) is among the major melliferous plant species prevailing in the ecosystems of central Arabia, including Saudi Arabia [2,3]. This plant is well adapted to harsh conditions, such as drought, high temperatures, and high salinity [4,5], and is abundant in the desert oases of Saudi Arabia. It is important for the preservation of wild fauna, as it represents a high-potential honey source and plays roles in facilitating insect diversity and pollination $[2,6,7]$.

Approximately 170 native species of the Ziziphus genus have been reported in tropical and subtropical regions of the world [8]. These species provide multipurpose benefits, 
such as conserving soil, stabilizing dunes, favoring the presence of perennial grasses, and serving as forage for livestock [5,9]. Plants of this genus are also used as fuel and construction materials; their edible fruits are eaten by humans; and the plants are used as medicine for some human and animal diseases due to their potent antimicrobial and analgesic properties [5,10-15]. These trees have the ability to tolerate and withstand harsh conditions such as heat, drought, and salinity [4,13].

The Rawdat-Khuraim oasis is located in central Saudi Arabia and represents a unique ecosystem within an arid desert. This oasis is a model nature preserve, providing an excellent and unique habitat for biodiverse animal and plant species. The floral diversity of this ecosystem harbors as many as 153 plant species of 32 families [16], and the region is an optimal area for potential studies of pollinator communities, including honey bees, due to its rich plant flora [16-18]. Pollinator diversity is crucial for reproduction processes of plants [19,20].

The foraging and production activities of honey bees are greatly influenced by the climatic conditions, the nature of flowering plants (the forage materials of bees), and the quantity of secreted nectar [7,21-23]. Nectar secretion is directly related to visitation by pollinators and weather conditions [24-27]. Honey bees show seasonal foraging activity patterns depending on the prevailing weather conditions [28]. A hot-dry environment exhibits differential effects on various honey bee species and subspecies [29,30].

The main objectives of this study were to investigate the foraging activities (outgoing and pollen-gathering activities) of two honey bee subspecies in the hot-dry environment of central Saudi Arabia during the abundant presence of Z. nummularia flora and to compare the activity patterns of the studied honey bee subspecies in relation to the weather conditions. The results of this study enhance our understanding of the flowering dynamics of bee plants in desert ecosystems and provide data for further studies aiming to improve beekeeping and honey production in arid environments.

\section{Materials and Methods}

\subsection{Experimental Area and Plant Species}

The field investigations were conducted at Rawdat-Khuraim, an oasis located $120 \mathrm{~km}$ northeast of Riyadh city, Saudi Arabia $\left(25^{\circ} 30^{\prime}-25^{\prime \prime} \mathrm{N}\right.$ and $47^{\circ} 46^{\prime}-30^{\prime \prime} \mathrm{E}$ at an elevation of 1817 feet) [3,22]. This oasis is approximately $18 \mathrm{~km}$ long and 1-2.5 km wide; during the flowering seasons of local flora, the climate is characterized as extremely dry (5-21\% RH) and hot $\left(23-52^{\circ} \mathrm{C}\right)$ [21]. The oasis is enriched with diverse plants dominated by populations of plant species associated with bee flora, such as Z. nummularia and Acacia gerrardii [17].

Z. nummularia (Burm. f.) is a melliferous plant that is widespread in the arid and semiarid regions of Saudi Arabia. Z. nummularia populations occur within other plant communities in the Rawdat-Khuraim oasis, and this species is mainly dependent on water from the estuaries in surrounding areas during winter, autumn and spring [16]. The highvalue honey extracted from Ziziphus spp. is locally called "Sidr honey" [31]. This research was carried out during the two flowering seasons of Z. nummularia, one from June-July (season I) and another from August-October (season II), over two years (2013-2015). Five trees (Z. nummularia) of the same reproductive age were randomly selected in the experimental area, and their trunks were tagged. These trees were freely accessible by honey bees, and potential floral visits by the bees were recorded during the two flowering seasons of Z. nummularia.

\subsection{Flowering Density}

The flowering density of Z. nummularia was measured at weekly intervals during the months from June-July (flowering Season I) and from August-October (flowering season II). The numbers of flowers on the five randomly selected Z. nummularia trees of the same reproductive age were counted, and the mean flowering density was calculated to show the flowering abundances and flowering density trends in the two seasons. 


\subsection{Honey Bee Subspecies}

Two honey bee subspecies were targeted to evaluate their field activities during Z. nummularia flowering. These subspecies were Apis mellifera jemenitica (AMJ; an indigenous subspecies of Saudi Arabia) and Apis mellifera carnica (AMC; an exotic subspecies often imported from Egypt). These species are well adapted environmentally and are domesticated in Saudi Arabia [32]. Five equal-strength colonies (five frames/colony) of each subspecies per season were randomly used in this study in each flowering season in 2013 and 2015. Modern wooden Langstroth hives were used to rear the selected colonies, and the colonies were kept sheltered under a sunshade in the Rawdat-Khuraim oasis for one month prior to the onset of each Z. nummularia flowering season in each year of study.

\subsection{Foraging (Outgoing and Incoming Pollen-Gathering) Activities of Honey Bees}

The total numbers of foraging (outgoing bees) and pollen-gathering (incoming bees loaded with pollen pellets) worker bees were counted over periods of one min/week in each tested colony throughout the flowering seasons of Z. nummularia trees using a counter and a stopwatch. The data were collected at five fixed times throughout the day for each tested colony according to Arabia Standard Time (AST). The five targeted times were labeled as sunrise (SR), forenoon (FN), noon (N), afternoon (AN) and sunset (SS) and took place at 5:30 h, 8:30 h, 11:30 h, 14:30 $\mathrm{h}$ and 17:30 h, respectively [32-36].

\subsection{Collection of Meteorological Data}

Temperature $\left({ }^{\circ} \mathrm{C}\right)$ and relative humidity $(\mathrm{RH})$ data were hypothesized to affect the foraging activities of the studied honey bees. These meteorological factor data were monitored in parallel to the collection of outgoing and pollen-gathering forager data. The meteorological data characterizing each year of study were obtained from a nearby weather station at King Khaled International Airport, and monthly and seasonal means were calculated.

\subsection{Thermal Window for Flight Activity}

The thermal windows for the flight activities of outgoing and pollen-gathering honey bees were calculated by counting the numbers of bees exiting and returning from the five colonies during the day at consistent ambient temperatures throughout the flowering season $[37,38]$. The thermal temperature ranges associated with the flight activities of the two honey bee subspecies (AMJ and $A M C$ ) were evaluated and compared.

\subsection{Statistical Analysis}

In the data analysis, the data were calculated and presented as means followed by standard errors. The data were processed for normality and homogeneity using the Kolmogorov-Smirnov and Levene tests, respectively, and compared by means of twoway ANOVA followed by Duncan's test using SPSS- $22{ }^{\circledR}$ statistical software. Statistical significance was indicated at $p<0.05, p<0.01$ and $p<0.001$.

\section{Results}

\subsection{Meteorological Data}

Temperature $\left({ }^{\circ} \mathrm{C}\right)$, relative humidity $(\%)$ and wind speed $(\mathrm{km} / \mathrm{h})$ observations were recorded during the flowering seasons of Z. nummularia from June-July (season I) and from August-October (season II). The observations revealed hot temperatures (with means of 38 and $36{ }^{\circ} \mathrm{C}$ and ranges of $26-46{ }^{\circ} \mathrm{C}$ and $21-44{ }^{\circ} \mathrm{C}$ in seasons I and II, respectively) and dry weather (with mean RH values of $9 \%$ and $11 \%$ and ranges of $4-20 \%$ and $4-30 \%$ in seasons I and II, respectively), with mean wind speeds of 13 and $10 \mathrm{~km} / \mathrm{h}$ (ranging from $0-28 \mathrm{~km} / \mathrm{h}$ and from 0-30 km/h) during flowering seasons I and II, respectively (Figure 1A). 

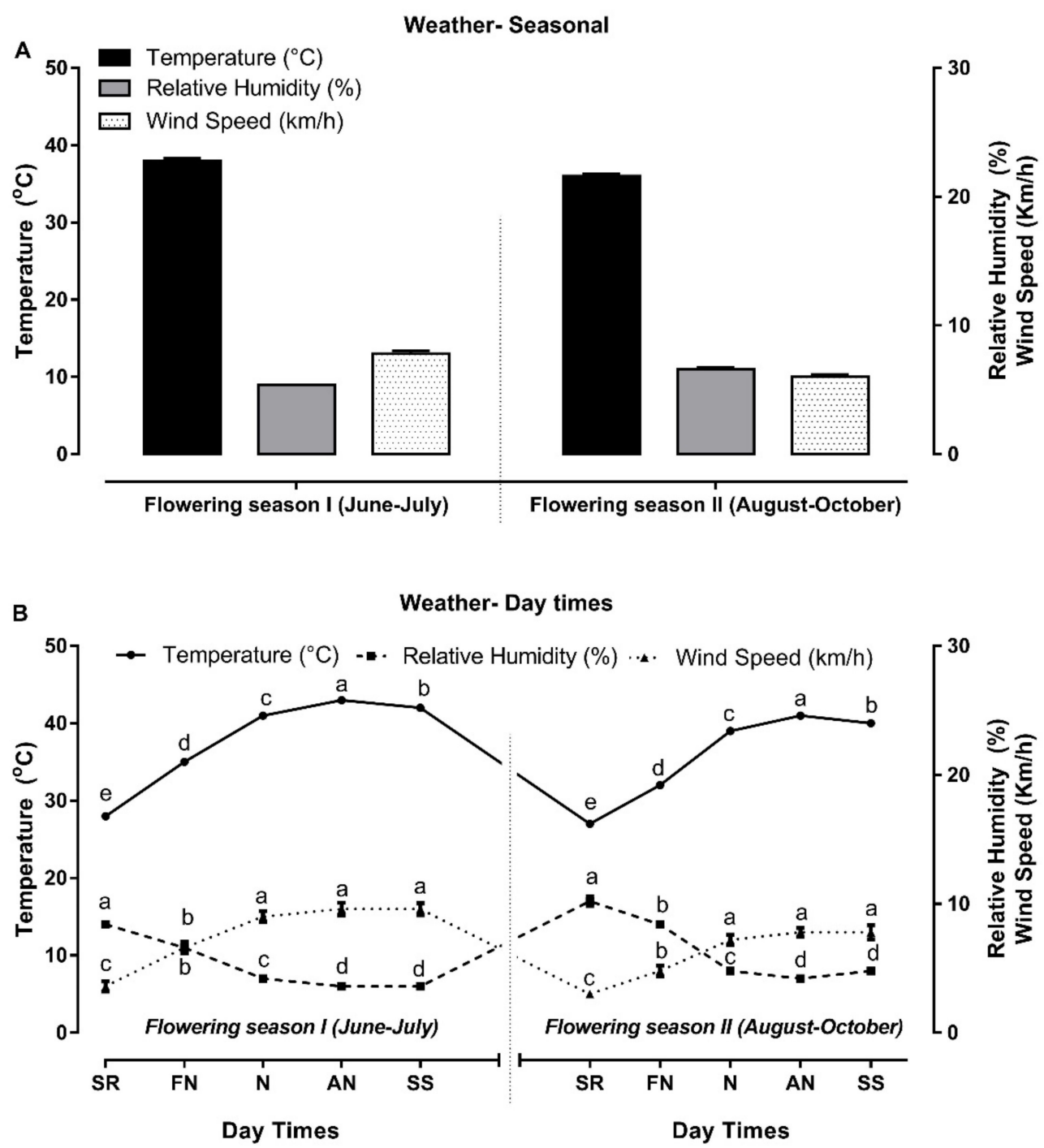

Figure 1. Meteorological temperature $\left({ }^{\circ} \mathrm{C}\right)$, relative humidity $(\%)$ and wind speed $(\mathrm{km} / \mathrm{h})$ data recorded during the flowering seasons of Z. nummularia in central Arabia. (A) Seasonal patterns of weather factors (mean \pm SEM) in each flowering season (season I and season II). (B) Daily patterns of weather factors (mean \pm SEM) registered at different times of day (SR: sunrise, FN: forenoon, $\mathrm{N}$ : noon, AN: afternoon, and SS: sunset). Different letters indicate significant differences among the mean values of a single weather factor at different times of day at $p<0.05$. SEM: standard error of the mean. Flowering season I was from June-July, and flowing season II was from August-October.

The hourly weather pattern revealed that the temperatures were significantly higher at noon (N), afternoon (AN) and sunset (SS) than at sunrise (SR) and forenoon (FN) during both flowering seasons. In both flowering seasons, the highest temperatures were recorded at the AN time and the lowest temperatures were recorded at the SR time. The relative humidity (RH) was significantly high at SR and gradually decreased to the lowest level later in the day during both seasons. The wind speed was significantly higher at N, AN and SS than at SR and FN during both flowering seasons (Figure 1B).

The monthly pattern of weather revealed that temperature was equally high during June, July, and August but was significantly lower during September and October (Figure 2A). RH was equally low during June, July, and August but significantly higher during September and October. The wind speed was significantly higher during July and August than during June, September and October (Figure 2A). Figure 2B shows the seasonal patterns of temperature, $\mathrm{RH}$ and wind speed in each month of the studied flowering seasons. 

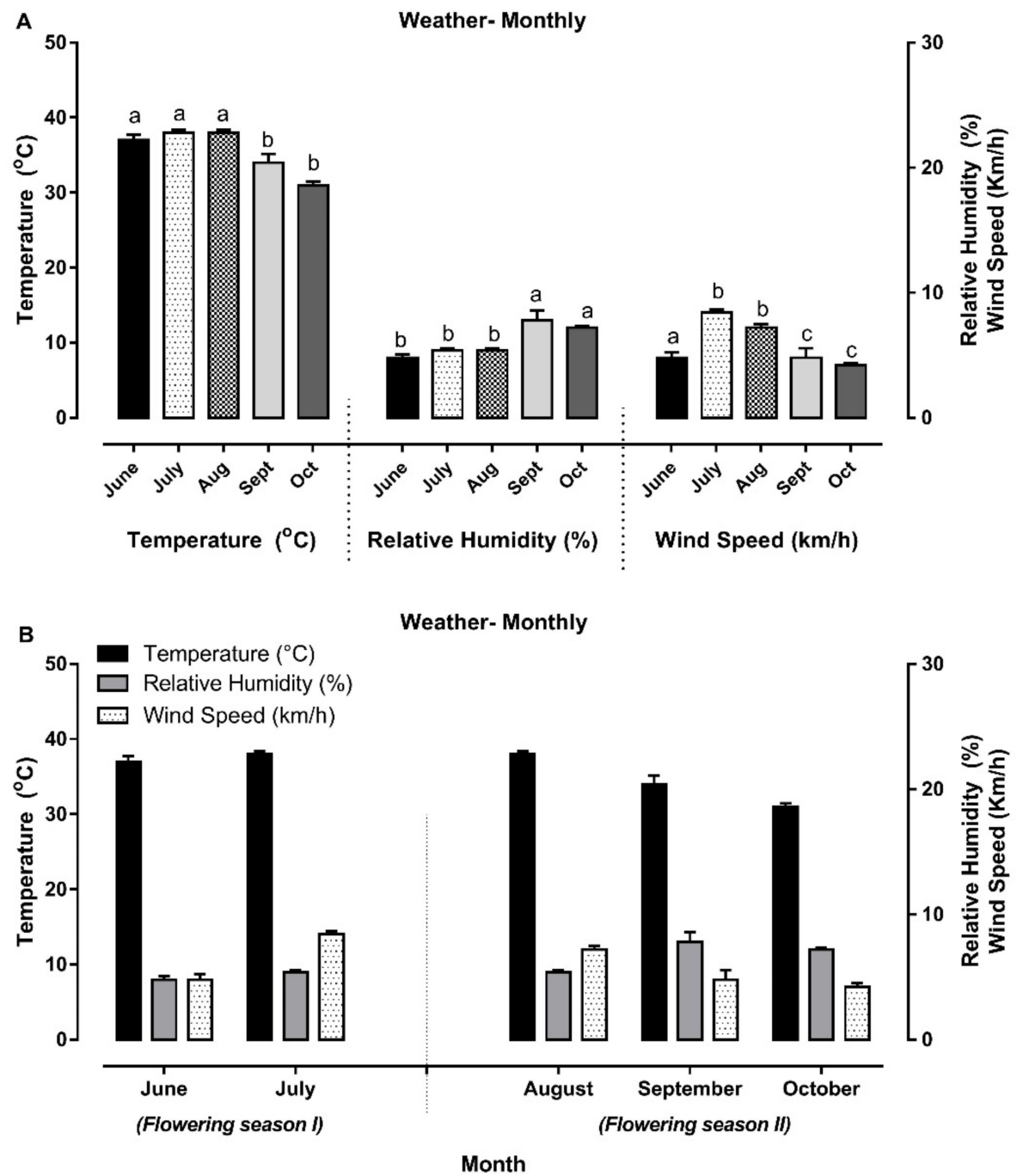

Figure 2. Monthly pattern of meteorological temperature $\left({ }^{\circ} \mathrm{C}\right)$, relative humidity $(\%)$ and wind speed $(\mathrm{km} / \mathrm{h})$ data recorded during the flowering seasons of Z. nummularia in central Arabia. (A) Monthly patterns of weather factors (mean \pm SEM). (B) Comparison of weather factors among different months (mean \pm SEM). Different letters indicate significant differences among monthly weather data within a group of single weather factors at $p<0.05$. SEM: standard error of the mean. Flowering season I was from June-July, and flowing season II was from August-October.

\subsection{Flowering Density of Z. nummularia}

The flowering density data (flowers $/ \mathrm{m}^{2}$ ) revealed two Z. nummularia flowering seasons: June-July (flowering season I) and August-October (flowering season II). Figure 3 clearly shows the flower abundance patterns of Z. nummularia in the two flowering seasons at weekly intervals during each month. The mean flowering density was significantly higher (404 flowers $/ \mathrm{m}^{2}$ ) during season II than during season I $\left(235\right.$ flowers $\left./ \mathrm{m}^{2}\right)$. During Season I, the flowering density ( 25 flowers $/ \mathrm{m}^{2}$ ) began increasing in June, reached a maximum ( 355 flowers $/ \mathrm{m}^{2}$ ) in mid-July and gradually declined throughout August (174 flowers $/ \mathrm{m}^{2}$ ) into the next flowering season. During Season II, the flowering density began increasing at the end of August, reached a maximum ( 877 flowers $/ \mathrm{m}^{2}$ ) in September and then gradually declined to a minimum of 32 flowers $/ \mathrm{m}^{2}$ in October. The highest mean flowering densities recorded in a month were measured in July (at 282 flowers $/ \mathrm{m}^{2}$ ) and September (546 flowers $/ \mathrm{m}^{2}$ ) for seasons I and II, respectively. 


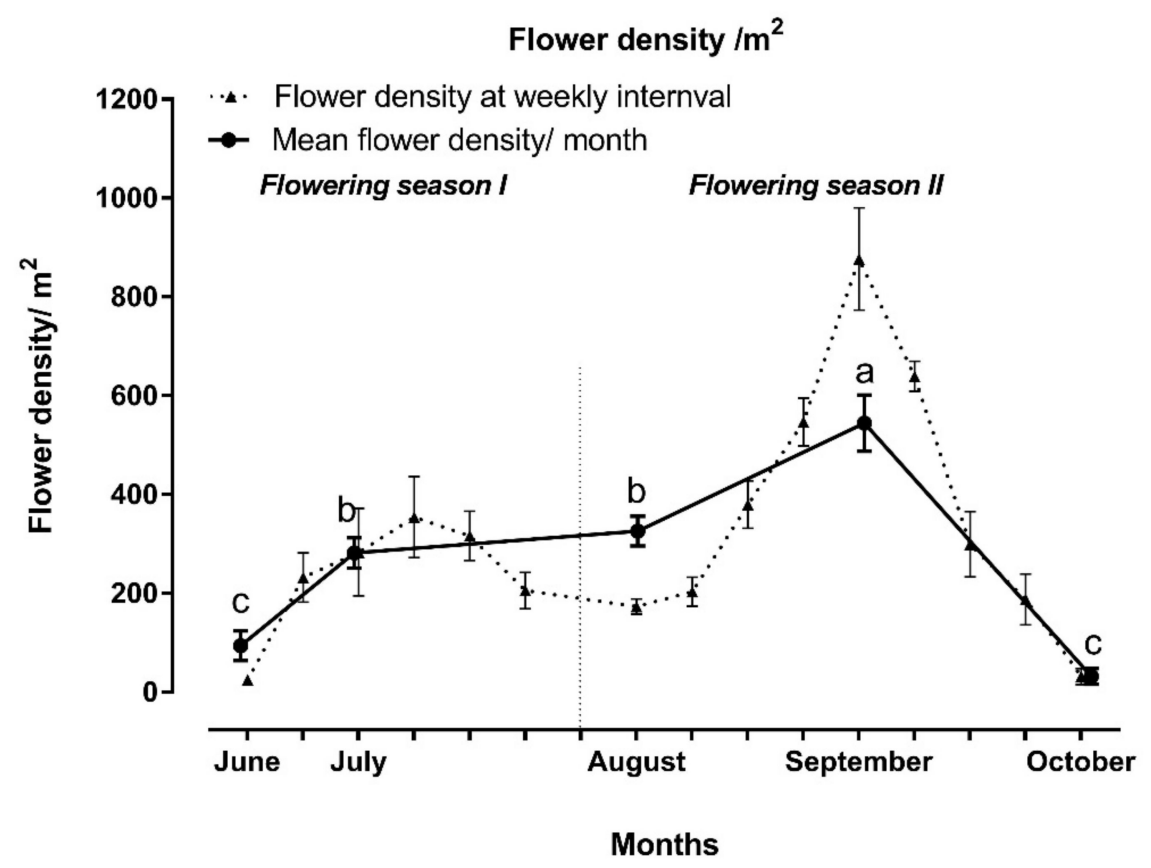

Figure 3. Flowering density (mean \pm SEM) of Z. nummularia during June-July (season I) and August-October (season II) in central Arabia. The mean flowering density/month was measured using flowering density values recorded at weekly intervals. Different letters indicate significant differences among the flower densities measured during different months at $p<0.05$.

\subsection{Foraging Activities}

The mean number of outgoing foragers and incoming pollen-gathering foragers of the two Apis subspecies were determined during the two Z. nummularia flowering seasons.

\subsubsection{Outgoing Foraging}

The outgoing foraging of native bees $(A M J)$ and exotic bees $(A M C)$ showed significant variations among different times throughout the day (SR, FN, N, AN and SS) during the flowering seasons of $Z$. nummularia. The outgoing foraging activities of both subspecies reached peak levels at SR and lowest levels at $\mathrm{N}$ during both flowering seasons (Figure 4A). The outgoing foraging activity of $A M J$ was significantly higher than that of $A M C$ during the daytime (SR and FN) in season I and during the daytime (SR, FN, AN and SS) in season II (Figure 4A). Taken together, $A M J$ exhibited significantly elevated outgoing foraging activity compared to $A M C$. The combined mean outgoing foraging activity (workers/colony/min) measured in the two flowering seasons revealed significantly higher outgoing foraging activity by $A M J(32.40 \pm 0.67$ workers/colony/min) than by $A M C$ (15.93 workers/colony/min \pm 1.20 ) (Figure 6A).

The monthly foraging activity of $A M J$ was significantly greater than that of $A M C$ throughout the months in the two Z. nummularia flowering seasons (Figure 4B). The monthly foraging activity increased gradually beginning in June, peaked during July and August, and declined steadily in September until reaching a minimum level in October (Figure 4B). The cumulative mean numbers of outgoing foraging workers of both bee subspecies were significantly higher in season I ( $27.43 \pm 1.21$ workers/colony/min) than in season II (21.71 \pm 0.86 workers/colony/min) (Figure 6B). 
A

Outgoing foraging- Day times
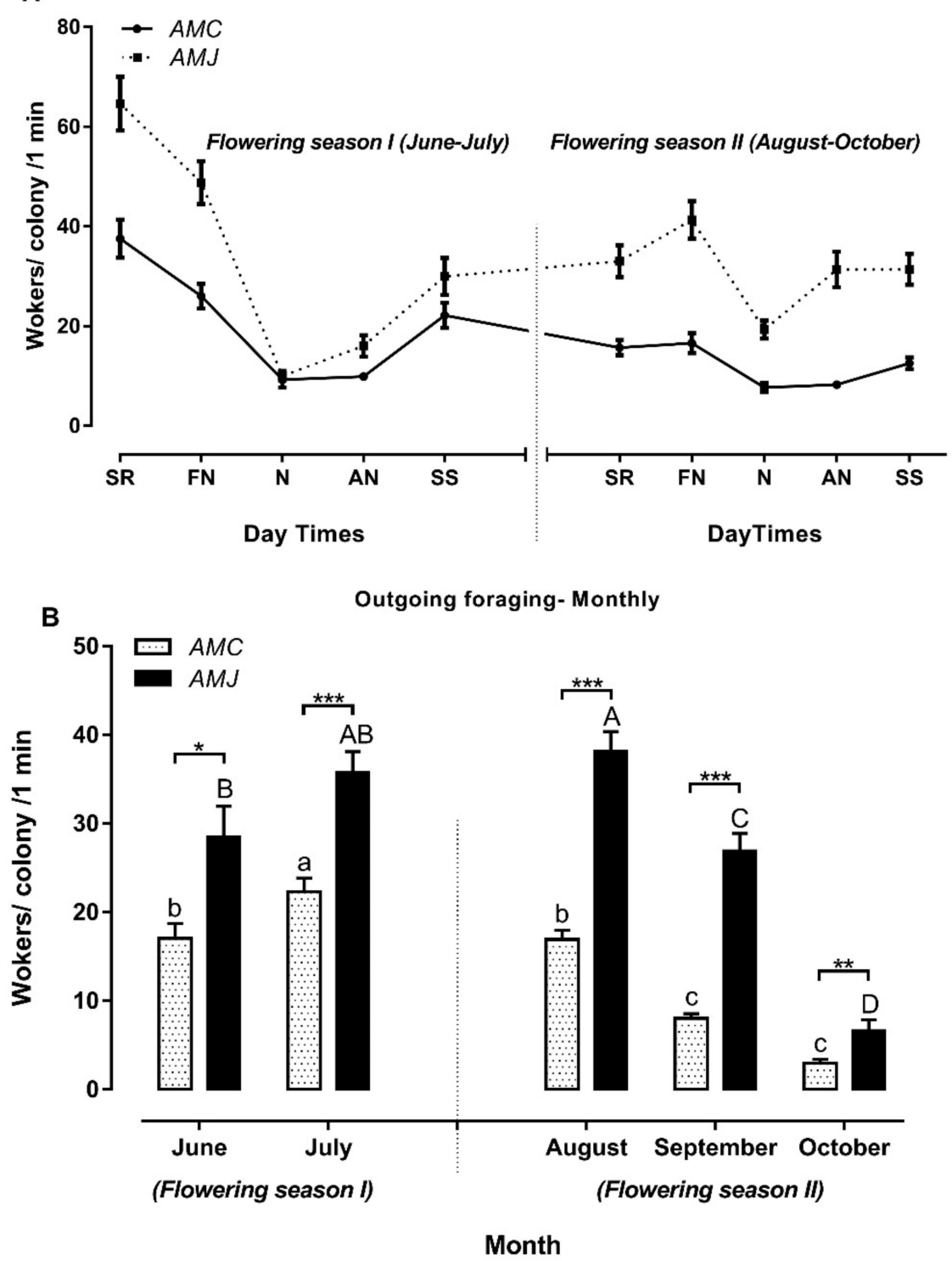

Figure 4. Outgoing foraging activities of two honey bee subspecies during the two flowering seasons of Z. nummularia in central Arabia. (A) Outgoing foraging activities (mean $\pm \mathrm{SEM}$ ) of $A M J$ and $A M C$ recorded at different times of day (SR: sunrise, FN: forenoon, N: noon, AN: afternoon, and SS: sunset). (B) Monthly values (mean $\pm \mathrm{SEM}$ ) of the outgoing foraging activities of $A M J$ and $A M C$ during the two flowering seasons (season I and season II). SEM: standard error of the mean. Flowering season I lasted from June-July, and flowering season II lasted from August-October. Different letters indicate significant differences among the foraging activities within each subspecies given in different columns at $p<0.05$. The asterisks indicate significant differences between the foraging activities of the two subspecies in a single month $\left({ }^{*} p<0.05 ;{ }^{* *} p<0.01 ;{ }^{* * *} p<0.001\right)$.

\subsubsection{Pollen-Gathering Foraging}

The native bees $(A M J)$ were more active in pollen-gathering than the exotic bees $(A M C)$ at all tested times of day (SR, FN, N, AN and SS) during both flowering seasons (season I and season II) of Z. nummularia. The pollen-gathering activities of both subspecies of honey bees (AMJ and $A M C$ ) were high at SR and low at SS during both flowering seasons (Figure 5A). The pollen-gathering foraging activities were much higher at $\mathrm{SR}$ during season I than at SR during season II for both honey bee subspecies (Figure 5A). The combined mean outgoing pollen-gathering activities in the two flowering seasons (workers/colony/min) were significantly higher for $A M J(4.88 \pm 0.40)$ than for $A M C(2.39 \pm 0.23)$ (Figure 6A). 

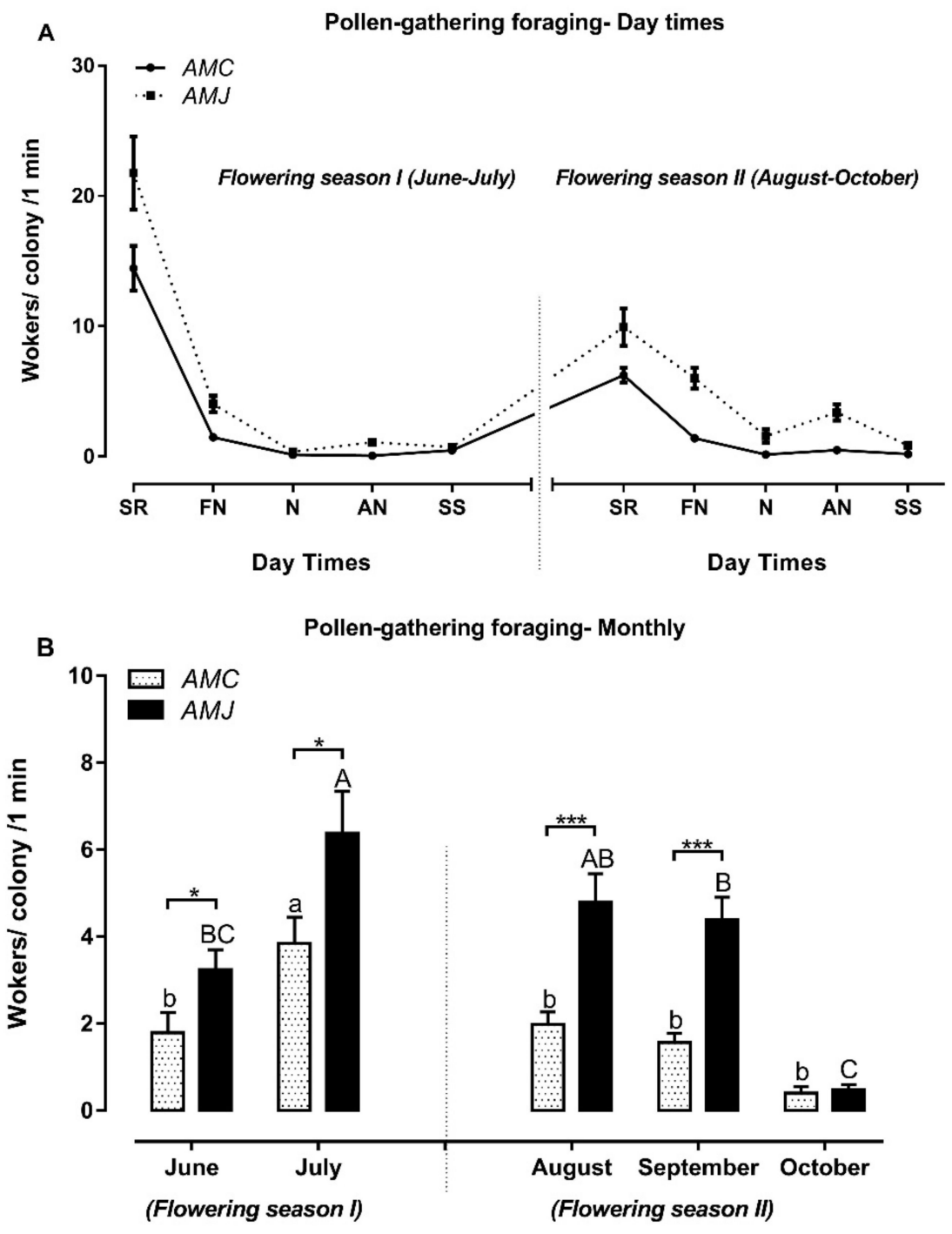

Month

Figure 5. Pollen-gathering activities of the two honey bee subspecies during the two flowering seasons of Z. nummularia in central Arabia. (A) Pollen gathering activities (mean \pm SEM) of AMJ and $A M C$ recorded at different times of day (SR: sunrise, FN: forenoon, N: noon, AN: afternoon, and SS: sunset). (B) Monthly values (mean \pm SEM) of the pollen-gathering activities of $A M J$ and $A M C$ during the two flowering seasons (season I and season II). SEM: standard error of the mean. Flowering season I lasted from June-July, and flowering season II lasted from August-October. Different letters indicate significant differences between the foraging activities of each subspecies given in different columns at $p<0.05$. The asterisks indicate significant differences between the two columns in each graph $\left({ }^{*} p<0.05 ;{ }^{* *} p<0.001\right)$.

The monthly pattern revealed significantly higher pollen gathering by $A M J$ compared to that by $A M C$ throughout the months in both flowering season I and flowering season II of Z. nummularia (Figure 5B). The monthly pollen-gathering activity increased gradually beginning in June, reached a peak in July, and declined steadily from AugustSeptember until reaching a minimum level in October (Figure 5B). The cumulative mean pollen-gathering foraging activities of both subspecies during the flowering seasons of Z. nummularia were higher $(4.46 \pm 0.45$ workers/colony/min) during season I than during season II (3.02 \pm 0.22 workers/colony/min) (Figure 6B). 

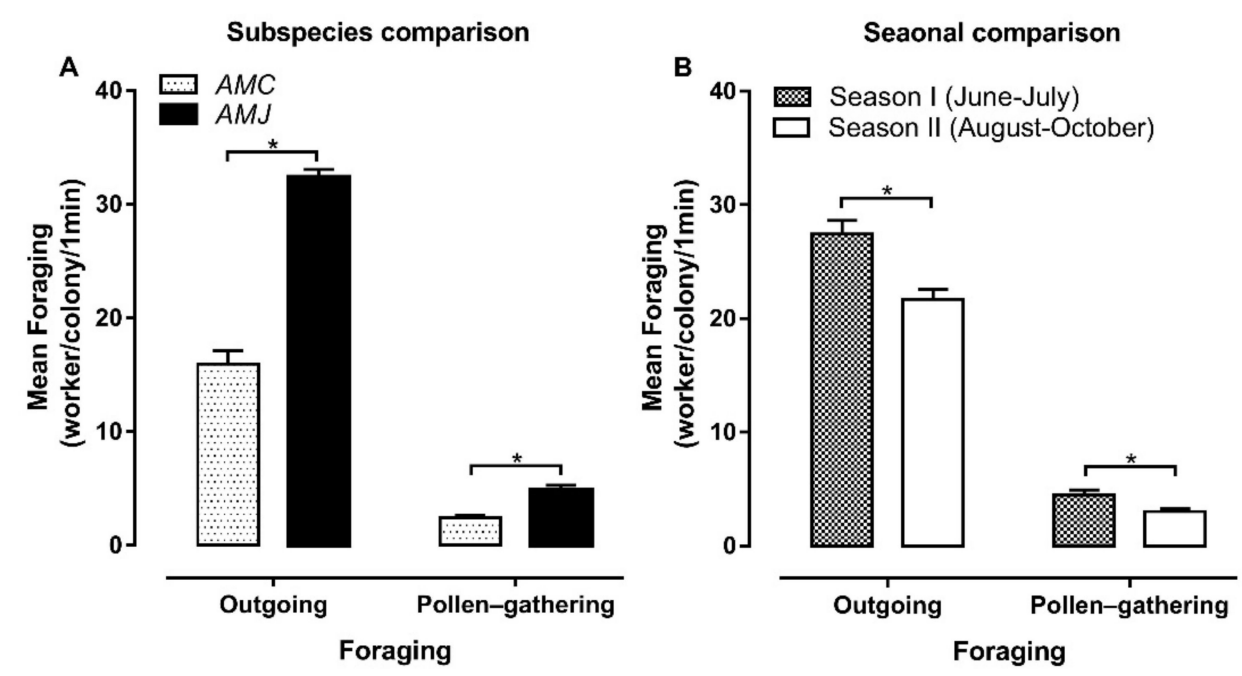

Figure 6. Comparison between the foraging activities (cumulative means for the two combined flowering seasons) of the two studied honey bee subspecies (AMJ and $A M C$ ) and the cumulative foraging activities of the subspecies combined during the two flowering seasons of Z. nummularia. (A) Foraging activities (mean $\pm \mathrm{SEM}$ ) of $A M J$ and $A M C$, regardless of season. (B) Seasonal comparison of foraging activities (mean \pm SEM) during the two flowering seasons (season I and season II) of Z. nummularia regardless of subspecies. SEM: standard error of the mean. Flowering season I lasted from June-July, and flowering season II lasted from August-October. The asterisks indicate significant differences between the two columns in each graph at $p<0.05$.

\subsection{Correlation Analysis}

Table 1 presents the correlation analysis among the outgoing foraging activities, pollengathering foraging activities and weather factors such as temperature (Temp.), relative humidity (RH) and wind speed (WS) observations. Temperature has a significant negative correlation with RH (-7.993) and a significant positive correlation with the WS (0.5412). RH shows a significant negative correlation $(-0.3786)$ with the WS. Temperature is significantly correlated with the outgoing and pollen-gathering foraging activities of $A M J$ ( 0.0760 and -0.1307 , respectively) and $A M C$ ( -0.0793 and -0.1665 , respectively). The two foraging activities (outgoing and pollen-gathering activities) of each bee subspecies were significantly positively correlated ( 0.5120 and 0.5039 for $A M C$ and $A M J$, respectively) with each other. Subsequently, the overall means calculated for the two subspecies also revealed a significant positive correlation (0.523) between these foraging activities.

Table 1. Pearson correlation coefficients among weather factors (temperature, relative humidity, and wind speed) and foraging activities (outgoing foraging and pollen gathering activities) of $A M J$ and $A M C$. The general means of the two subspecies revealed a positive significant correlation $\left(0.523^{* * *}\right)$ between outgoing foraging and pollen-gathering activities. The asterisks indicate significant correlations $\left({ }^{*} p<0.05,{ }^{* *} p<0.01,{ }^{* * *} p<0.001\right)$. ${ }^{\text {a Temperature; }}{ }^{\mathrm{b}}$ relative humidity; ${ }^{c}$ Wind speed.

\begin{tabular}{|c|c|c|c|c|c|}
\hline \multirow{2}{*}{ Subspecies } & \multirow{2}{*}{ Foraging Activity } & \multicolumn{4}{|c|}{ Correlation Coefficient (r) and Significance } \\
\hline & & Temp. ${ }^{a}$ & RH $^{\mathbf{b}}$ & WS $^{\mathrm{c}}$ & Outgoing \\
\hline \multirow{2}{*}{$A M C$} & Outgoing & $-0.0793 * *$ & $0.1105^{* *}$ & $0.1032 * *$ & - \\
\hline & Pollen-gathering & $-0.1665^{* * *}$ & $0.1661^{* *}$ & -0.0442 & $0.5120 * *$ \\
\hline \multirow{2}{*}{$A M J$} & Outgoing & $0.0760 * *$ & -0.0662 & $0.0748^{*}$ & - \\
\hline & Pollen-gathering & $-0.1307^{* *}$ & $0.1303^{* *}$ & -0.0629 & $0.5039 * *$ \\
\hline \multirow{3}{*}{ Weather factors } & Temp. $^{\text {a }}$ & & $-7.993 * *$ & $0.5412^{* *}$ & \\
\hline & $\mathrm{RH}^{\mathrm{b}}$ & $-7.993 * *$ & & $-0.3786^{* *}$ & \\
\hline & WS $^{\mathrm{c}}$ & $0.5412 * *$ & $-0.3786 * *$ & & \\
\hline
\end{tabular}




\subsection{Thermal Windows of Flight Activity}

Due to the adaptations of the studied honey bee subspecies to different climate zones, the thermal windows of foraging flight activities (bee exiting and returning to hives during the day) differed between $A M J$ and $A M C$. Considering the numbers of bees leaving the nests (outgoing foraging bees) at a given ambient temperature, we found overlapping thermal windows (defined as the temperature range in which $90 \%$ of flight activities occur) for the two honey bee subspecies (Figure 7). High numbers of individual $A M J(22,677)$ and $A M C(11,150)$ bees were observed, and both subspecies were found to be active in the temperature range of $27-43^{\circ} \mathrm{C}$ with mean peak activities at 35.5 and $35.3^{\circ} \mathrm{C}$, respectively. Despite the overlapping patterns with similar values, due to the high number of bees that were evaluated, there was a significant difference ( $t$-test: $t=2.8 ; d f=33,825 ; p=0.005$ ) between the honey bee subspecies regarding their outgoing foraging thermal windows.

Thermal window of flight activity
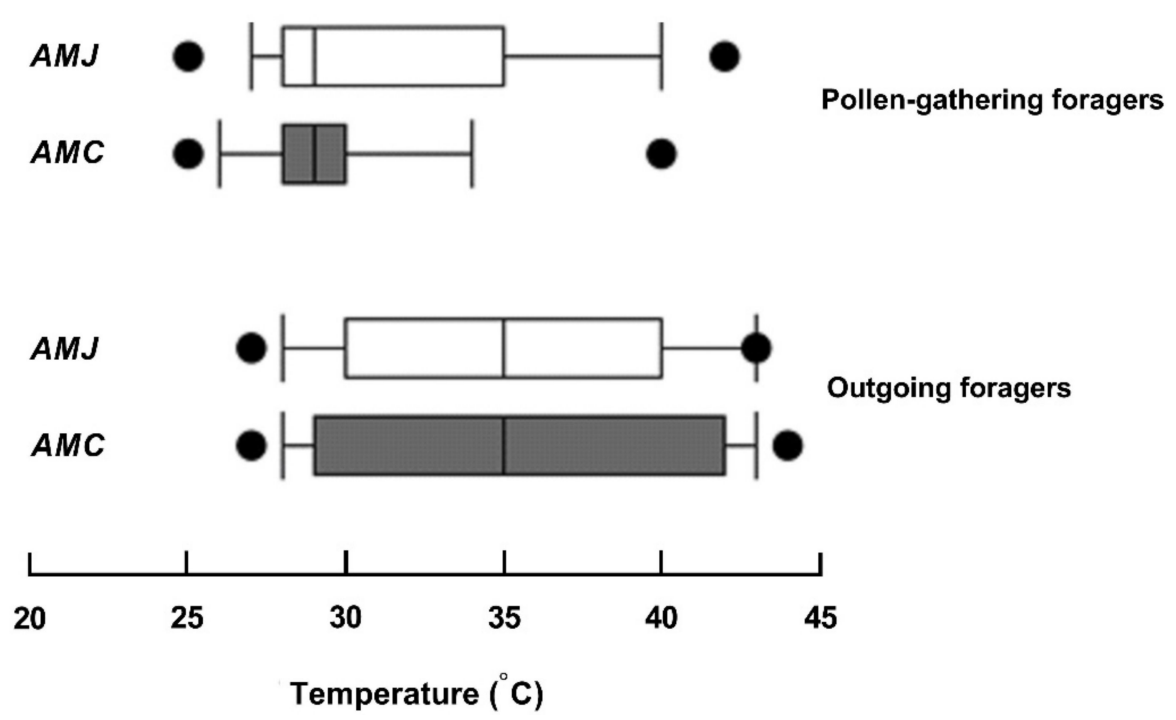

Figure 7. Thermal windows of the foraging flight activities of $A M J$ and $A M C$ during the flowering seasons of Z. nummularia under hot-arid environmental conditions. The lower panel represents the number of foragers leaving the nests (outgoing foragers), and the upper panel represents the pollen-gathering foragers returning to the nests. The boxes represent the temperature range in which $50 \%$ of the foraging activities occurred, and the whiskers indicate the $80 \%$ range, while the outliers show the $90 \%$ range.

The thermal windows of the flight activities of returning foragers (pollen-gathering foragers) were between 25 and $42{ }^{\circ} \mathrm{C}$ (peak activity: $31.4^{\circ} \mathrm{C}$ ) for $A M J$ and between 25 and $40{ }^{\circ} \mathrm{C}$ (peak activity: $29.6{ }^{\circ} \mathrm{C}$ ) for $A M C$ (Figure 7). The main pollen-foraging activities ( $50 \%$ of individuals) of $A M C$ bees occurred in a narrow range between 28 and $30^{\circ} \mathrm{C}$, while the main activities of $A M J$ bees occurred between 28 and $30^{\circ} \mathrm{C}$. A significant difference ( $t$-test: $\mathrm{t}=12.5 ; \mathrm{df}=5090 ; p=0.001$ ) was found between the honey bee subspecies regarding their pollen foraging activity thermal windows.

\section{Discussion}

Z. nummularia is a dominant bee-forage plant in the Rawdat-Khuraim oasis in Saudi Arabia, in addition to other plants, especially Acacia spp. [17,22,39]. The experimental oasis was surrounded by a hot and dry environment during the $Z$. nummularia flowering seasons [3]. 


\subsection{Flowering Density}

In the present study, the flowering density of Z. nummularia reflected two flowering seasons that were categorized into two seasons: season I (from June to July) and season II (from August to October). This was in agreement with the findings of Hassan, et al. [3], who also reported the onset of flowering from June to October in two seasons. The flowering density was higher during flowering season II than during flowering season I. The longevity of Z. nummularia flowers was found to be two days, with $83 \%$ nectar secretion occurring on the first day and $17 \%$ occurring on the second day of the blooming period [2]. Thus, Z. nummularia can produce sufficient flowers even under harsh climatic conditions [3,7].

\subsection{Foraging Activities}

The foraging activities (outgoing foraging and pollen-gathering activities) of the two studied honey bee species ( $A M J$ and $A M C$ ) revealed that both species performed foraging activities well in hot, dry, and windy environments in the presence of abundant Z. nummularia flora. These subspecies also performed well under identical weather conditions in the presence of abundant Acacia flora [22]. Honey bees are able to survive and produce honey even under harsh climatic factors when encouraged by the flowering of rich nectar sources [40], and peak worker visitation takes place when ample food sources are available [41].

We observed that $A M J$, a native bee of Saudi Arabia, exhibited significantly higher foraging activities (outgoing and pollen-gathering activities) than the exotic European bee $(A M C)$ in the presence of abundant Zizyphus flowers during the flowering seasons of the studied plant species (June-October). Frequent foraging activities on Z. nummularia flowers by $A M J$ were reported from August-October compared with those of $A M C$ [2], and the foraging rate of $A M J$ was previously found to be greater than that of $A M C$ on Acacia flowers [22]. The variations in the levels of foraging activity between these two subspecies may be explained by considering the adaptation levels and morphological and physiological traits of these subspecies. $A M J$ is well adapted to the local climatic conditions of Saudi Arabia, while $A M C$ is well known for its adaptation to the temperate climate of central Europe [22,29,42].

Other potential factors inducing differential foraging between honey bee subspecies include the higher population density (strength) of the $A M J$ colonies than that of the $A M C$ colonies; consequently, a larger number of $A M J$ bees were at foraging age at the time of this study. It was further assumed that if the population densities of the two subspecies were considered identical, then these findings may indicate that a larger proportion of $A M C$ workers may have been engaged in other activities inside their nests, such as thermoregulation or brood care, or were simply inactive. $A M J$ bees are well adapted to harsh native environmental conditions and have better tolerance to high temperatures than $A M C$ bees, as the $A M C$ subspecies has a lower temperature threshold $[29,34,43]$. Therefore, the increased thermoregulation of $A M C$ compared to that of $A M J$ may induce differences in the optimal brood temperature within the nests. To avoid fatal body overheating, $A M C$ bees reduce their activity levels and, consequently, their production of metabolic heat. This also explains the adaptation of the morphological and physiological traits of the native bee subspecies to $[29,44]$.

\subsection{Effect of Weather on Foraging}

\subsubsection{Foraging and Time of Day}

The different honey bee subspecies examined in this study countered hot and dry weather conditions differently during the abundant flowering season [3]. We found that weather conditions exerted a significant effect on the foraging and pollen-gathering activities of both bee subspecies in abundant $Z$. nummularia flora. This resulted in variations in honey bee foraging patterns hourly (time of day), monthly and seasonal levels. The outgoing and pollen-gathering foraging activities of $A M J$ bees were significantly higher than those of $A M C$ bees during each month (June-October) in the flowering seasons. The 
daily patterns concerning the numbers of bees leaving the nests differed between the two seasons. The daytime fluctuations in the outgoing and pollen-gathering foraging activities of $A M J$ and $A M C$ during the flowering seasons of $Z$. nummularia were comparable with the daytime fluctuations in nectar and pollen-gathering foraging activities observed during the flowering of Acacia spp. [22]. The outgoing and pollen-gathering foraging activities of both honey bee subspecies were higher at sunrise (SR) than at other times of day during both flowering seasons. Flower-opening in Z. nummularia has been reported to start just before SR and continue until SS [2], which could explain the reason for the higher foraging activity observations at SR. A reasonable quantity of nectar attracts more floral pollinators [27], and it is presumed that the opening of more flowers offers more nectar at SR, resulting in high foraging activities at SR. In addition, the role of weather conditions (such as temperature and humidity) cannot be ignored at the onset of foraging activities because weather factors significantly affect the nectar quantity $[25,45]$.

\subsubsection{Foraging and Flowering Season}

Given the elevated foraging availability and high flowering density of melliferous Z. nummularia in season II, it was hypothesized that foraging (outgoing and pollengathering) activities may increase from flowering season I (June-July) to flowering season II (August-October). However, this was not the case; we found no evidence of any increased foraging activities during season II. Surprisingly, the foraging activity was considerably high in season I (June-July). Hassan, et al. [3] reported peak nectar production of Z. nummularia during July, which might explain the high foraging activity trend observed in season I. This trend reflected that the observed foraging activity across flowering seasons might not be explained only by the availability of sufficient food. A plausible explanation for the observed differences in the seasonal foraging patterns could include the differences in foraging fauna and temperatures between the flowering two seasons. In addition, the elevated pollen intake during season I might have caused an increase in brood production. Thus, more workers might have been engaged in brood rearing in season II than in season I. An alternative explanation could be a general reduction in the bee populations from season I to season II. It is believed that under the extreme weather conditions of oases with high temperature and low humidity values, the noticeable foraging activities of $A M J$ and $A M C$ were only possible due the abundance of nectar-rich Z. nummularia plants in the experimental area. The differential foraging trends observed during each month (June to October) could have been associated with the fluctuating monthly nectar secretion rate of the flowering plants $[22,46]$.

\subsection{Correlation and Thermal Activity}

The correlations between the outgoing and pollen-gathering foraging activities of the two bee subspecies were significantly positive. The correlations between the temperature and RH (negative), between the temperature and WS was significant (positive), and between RH and the WS (negative) were significant. These findings are in agreement with those of Alqarni [22], who reported comparable correlations between weather parameters and the foraging of bees on Acacia nectar. Although the tested honey bee subspecies exhibited overlapping flight activity thermal windows, the thermal windows of $A M J$ and $A M C$ differed for outgoing and pollen-gathering foraging activities (the subspecies had thermal ranges of $27-43^{\circ} \mathrm{C}$ and $25-42{ }^{\circ} \mathrm{C}$, respectively). This shows that foragers are able to survive and forage at high temperatures. Previous studies on the thermal tolerance of honey bees have shown that the $A M J$ and $A M C$ subspecies were able to tolerate very high temperatures exceeding $50{ }^{\circ} \mathrm{C}$ [29]; temperatures this high were never reached in the present study. The present research helps to understand the performance of honey bees and their association with weather conditions and nectar-rich flora. More studies are needed to explore the responses of bee foragers to Ziziphus flowers and the potential of these honey bee subspecies colonies to produce honey during Ziziphus flowering. 


\section{Conclusions}

We conclude that weather has a substantial influence on the outgoing and pollengathering foraging activities of honey bees. The foraging of honey bees was found to be variable at different times of day, with high foraging observed at sunrise. Z. nummularia, a melliferous plant, has a high flowering density from August-October. $A M J$ was showed higher outgoing and pollen-gathering foraging activities than $A M C$ during each month of the flowering seasons of $Z$. nummularia. The thermal windows for the foraging flight activities of the two honey bee subspecies were significantly different. The outgoing and pollen-gathering foraging activities of each bee species were positively correlated with each other. These outcomes will help researchers understand the relationships among bee foraging, weather conditions and the abundance of nectar-rich flora.

Author Contributions: Conceptualization, A.S.A. and J.I.; methodology, A.M.A.H., A.A.O. and H.S.R.; validation, A.S.A. and J.I.; formal analysis, J.I. and A.M.A.H.; investigation, H.S.R., A.M.A.H., A.A.O. and J.I.; resources, A.S.A.; writing—original draft preparation, A.M.A.H. and J.I.; writingreview and editing, J.I. and A.S.A.; visualization, A.S.A.; supervision, A.S.A.; project administration, A.S.A., A.A.O. and J.I.; funding acquisition, A.S.A. All authors have read and agreed to the published version of the manuscript.

Funding: This research was funded by the Deanship of Scientific Research at King Saud University, Riyadh, Saudi Arabia through research group project No. RGP-189.

Institutional Review Board Statement: Not applicable.

Informed Consent Statement: Not applicable.

Data Availability Statement: Data available on request due to privacy restrictions.

Acknowledgments: The authors extend their appreciation to the Deanship of Scientific Research at King Saud University for funding the work through research group project No. RGP-189.

Conflicts of Interest: The authors declare no conflict of interest.

\section{References}

1. Attfield, H.H.D. A Beekeeping Guide for the Tropics and Subtropics; Vita Publication: Washington, DC, USA, 2001.

2. Alqarni, A.S. Honeybee foraging, nectar secretion, and honey potential of wild jujube trees, Ziziphus nummularia. Neotrop. Entomol. 2015, 44, 232-241. [CrossRef]

3. Hassan, A.M.A.; Giovanetti, M.; Raweh, H.S.A.; Owayss, A.A.; Ansari, M.J.; Nuru, A.; Radloff, S.E.; Alqarni, A.S. Nectar secretion dynamics of Ziziphus nummularia: A melliferous species of dry land ecosystems. Saudi J. Biol. Sci. 2017, 24, 1470-1474. [CrossRef] [PubMed]

4. Hammer, K. Rhamnaceae. In Mansfeld's Encyclopedia of Agricultural and Horticultural Crops; Mansfeld, R., Hanelt, P., Institute of Plant Genetics and Crop Plant Research, Eds.; Springer: Berlin, Germany, 2001; pp. 1141-1150.

5. Pandey, A.; Singh, R.; Radhamaniand, J.; Bhandari, D.C. Exploring the potential of Ziziphus nummularia (Burm. f.) Wight et Arn. from drier regions of India. Genet. Resour. Crop Evol. 2010, 57, 929-936. [CrossRef]

6. Owayss, A.A. Diversity of insect floral visitors and their role in pollination of wild jujube, Ziziphus nummularia (Burm. F. Wight et Arn.) in hot-dry environment. Bull. Entomol. Soc. Egypt 2015, 92, 23-35.

7. Adgaba, N.; Awad, A.M.; Al-Ghamdi, A.A.; Alqarni, A.S.; Radloff, S.E. Nectar of Ziziphus spina-christi (L.) willd (Rhamnaceae): Dynamics of secretion and potential for honey production. J. Apic. Sci. 2012, 56, 49-59. [CrossRef]

8. Tel-Zur, N.; Schenider, B. Floral biology of Ziziphus mauritiana (Rhamnaceae). Sex. Plant Reprod. 2009, 22, 73-85. [CrossRef]

9. Singh, M.; Dwivedi, R.N. Farmers preferences on tree/crop species and livestock feeding-A study through pra approach. Progress. Agric. 2002, 2, 135-137.

10. Shokrollahi, A.; Alizadeh, A.; Malekhosseini, Z.; Ranjbar, M. Removal of Bromocresol Green from aqueous solution via adsorption on Ziziphus nummularia as a new, natural, and low-cost adsorbent: Kinetic and thermodynamic study of removal process. J. Chem. Eng. Data 2011, 56, 3738-3746. [CrossRef]

11. Chanda, S.; Kaneria, M.; Vaghasiya, Y.K. Evaluation of antimicrobial potential of some Indian medicinal plants against some pathogenic microbes. Indian J. Nat. Prod. Resour. 2011, 2, 225-228.

12. Arndt, S.K.; Clifford, S.C.; Popp, M. Ziziphus-A Multipurpose Fruit Tree for Arid Regions. In Sustainable Land Use in Deserts; Springer: Berlin/Heidelberg, Germany, 2001; pp. 388-399.

13. Saied, A.S.; Gebauer, J.; Hammer, K.; Buerkert, A. Ziziphus spina-christi (L.) Willd.: A multipurpose fruit tree. Genet. Resour. Crop Evol. 2008, 55, 929-937. [CrossRef] 
14. Bachaya, H.A.; Iqbal, Z.; Khan, M.N.; Sindhu, Z.U.; Jabbar, A. Anthelmintic activity of Ziziphus nummularia (bark) and Acacia nilotica (fruit) against Trichostrongylid nematodes of sheep. J. Ethnopharmacol. 2009, 123, 325-329. [CrossRef]

15. Shah, A.H.; Tariq, M.; Al-Yahya, M.A. Studies on the alkaloidal fraction from the stem bark of Zizyphus nummularia. Fitoterapia 1990, 61, 452-469.

16. Alfarhan, A.H. A floristic account on Raudhat Khuraim central province Saudi Arabia. Saudi J. Biol. Sci. 2001, 8, 80-103.

17. Al-Farraj, M.M.; Al-Farhan, A.; Al-Yemeni, M. Ecological studies on Rawdhat system in Saudi Arabia I-Rawdhat Khorim. Pak. J. Bot. 1997, 29, 75-88.

18. Shaltout, K.H.; Mady, M.A. Current situation of the raudha's woody plant populations in the Central Saudi Arabia. Feddes Repert. 1993, 104, 503-509. [CrossRef]

19. Brunet, J.; Sweet, H.R. Impact of insect pollinator group and floral display size on outcrossing rate. Evolution 2006, 60, 234-246. [CrossRef]

20. Gómez, J.M.; Bosch, J.; Perfectti, F.; Fernández, J.; Abdelaziz, M. Pollinator diversity affects plant reproduction and recruitment: The tradeoffs of generalization. Oecologia 2007, 153, 597-605. [CrossRef]

21. Awad, A.M.; Owayss, A.A.; Alqarni, A.S. Performance of two honey bee subspecies during harsh weather and Acacia gerrardii nectar-rich flow. Sci. Agric. 2017, 74, 474-480. [CrossRef]

22. Alqarni, A.S. Differential foraging of indigenous and exotic honeybee (Apis mellifera L.) races on nectar-rich flow in a subtropical ecosystem. Insects 2020, 11, 254. [CrossRef] [PubMed]

23. Abou-Shaara, H.F.; Owayss, A.A.; Ibrahim, Y.Y.; Basuny, N.K. A review of impacts of temperature and relative humidity on various activities of honey bees. Insectes Soc. 2017, 64, 455-463. [CrossRef]

24. Nicolson, S.W.; Nepi, M.; Pacini, E. Nectaries and Nectar; Springer: Dordrecht, The Netherlands, 2007.

25. Langernberger, M.W.; Davis, A.R. Temporal changes in floral nectar production, reabsorption, and compostion associated with dichogamy in annual caraway (Carum carvi: Apiaceae). Am. J. Bot. 2002, 89, 1588-1598. [CrossRef]

26. Rathcke, B.J. Nectar distributions, pollinator behavior, and plant reproductive success. In Effects of Resource Distribution on Animal-Plant Interactions; Hunter, M.D., Ohgushi, T., Price, P.W., Eds.; Academic Press: Boston, MA, USA, $1992 ;$ pp. 113-138.

27. Boisvert, M.J.; Veal, A.J.; Sherry, D.F. Floral reward production is timed by an insect pollinator. Proc. R. Soc. B 2007, $274,1831-1837$. [CrossRef]

28. Schneider, S.S.; McNally, L.C. Seasonal patterns of foraging activity in colonies of the African honey bee, Apis mellifera scutellata, in Africa. Insectes Soc. 1992, 39, 181-193. [CrossRef]

29. Alqarni, A.S. Tolerance of summer temperature in imported and indigenous honeybee Apis mellifera L. races in central Saudi Arabia. Saudi J. Biol. Sci. 2006, 13, 123-127.

30. Corbet, S.A.; Fussell, M.; Ake, R.; Fraser, A.; Gunsen, C.; Salvage, A.; Smithy, K. Temperature and pollination activity of social bees. Ecol. Entomol. 1993, 18, 17-30. [CrossRef]

31. Owayss, A.A.; Elbanna, K.; Iqbal, J.; Abulreesh, H.H.; Organji, S.R.; Raweh, H.S.; Alqarni, A.S. In vitro antimicrobial activities of Saudi honeys originating from Ziziphus spina-christi L. and Acacia gerrardii Benth. trees. Food Sci. Nutr. 2020, 8, 390-401. [CrossRef] [PubMed]

32. Alqarni, A.S.; Balhareth, H.M.; Owayss, A.A. Performance evaluation of indigenous and exotic honey bee (Apis mellifera L.) races in Assir region, southwestern Saudi Arabia. Saudi J. Biol. Sci. 2014, 21, 256-264. [CrossRef]

33. Beekman, M.; Sumpter, D.J.T.; Seraphides, N.; Ratnieks, F.L.W. Comparing foraging behaviour of small and large honey-bee colonies by decoding waggle dances made by foragers. Funct. Ecol. 2004, 18, 829-835. [CrossRef]

34. Ali, M.A.M. Comparative study for evaluating two honey bee races, Apis mellifera jementica (indigenous race) and Apis mellifera carnica (carniolan race) in brood production, population development and foraging activity under the environmental conditions of the central region of the Kingdom of Saudi Arabia. Ann. Agric. Sci. 2011, 56, 127-134. [CrossRef]

35. Malerbo-Souza, D.T. The corn pollen as a food source for honeybees. Acta Sci. Agron. 2011, 33, 701-704. [CrossRef]

36. Pearce, F.C.R.; Couvillon, M.J.; Ratnieks, F.L.W. Hive relocation does not adversely affect honey bee (Hymenoptera: Apidae) foraging. Psyche 2013, 2013, 8. [CrossRef]

37. Woyke, J. Diurnal flight activity of African bees Apis mellifera adansonii in different seasons and zones of Ghana. Apidologie 1992, 23, 107-117. [CrossRef]

38. Dukku, U.; Russom, Z.; Domo, A.G. Diurnal and seasonal flight activity of the honeybee, Apis Mellifera L, and its relationship with temperature, light intensity and relative Humidity in the Savanna of Northern Nigeria. Glob. J. Sci. Front. Res. 2013, 13, 1-7.

39. Alatar, A.A.; El-Sheikh, M.A.R.; Thomas, J.; Hegazy, A.K.; El Adawy, H.A. Vegetation, floristic diversity, and size-classes of Acacia gerrardii in an arid wadi ecosystem. Arid Land Res. Manag. 2015, 29, 335-359. [CrossRef]

40. Hassan, A.M.A. Ecological Studies on Honey Bee Apis Mellifera L. Activities on Talh Trees Acacia Gerrardii (Benth.) and Use of Geographic Information Systems and Remote Sensing Technology to Assess Foraging Capacity for Honey Production. PhD Thesis, College of Food and Agriculture Sciences, King Saud University, Riyadh, Saudi Arabia, 2016.

41. Silva, D.P.; Moisan-De Serres, J.; Souza, D.R.; Hilgert-Moreira, S.B.; Fernandes, M.Z.; Kevan, P.G.; Freitas, B.M. Efficiency in pollen foraging by honey bees: Time, motion and pollen depletion on flowers of Sisyrinchium palmifolium Linnaeus (Asparagales: Iridaceae). J. Pollinat. Ecol. 2013, 11, 27-32. [CrossRef] 
42. Adgaba, N.; Al-Ghamdi, A.; Tadesse, Y.; Getachew, A.; Awad, A.M.; Ansari, M.J.; Owayss, A.A.; Mohammed, S.E.A.; Alqarni, A.S. Nectar secretion dynamics and honey production potentials of some major honey plants in Saudi Arabia. Saudi J. Biol. Sci. 2017, 24, 180-191. [CrossRef]

43. Alqarni, A.S.; Hannan, M.A.; Owayss, A.A.; Engel, M.S. The indigenous honey bees of Saudi Arabia (Hymenoptera, Apidae, Apis mellifera jemenitica Ruttner): Their natural history and role in beekeeping. Zookeys 2011, 134, 83-98. [CrossRef]

44. Abou-Shaara, H.F.; Al-Ghamdi, A.A.; Mohamed, A.A. Tolerance of two honey bee races to various temperature and relative humidity gradients. Environ. Exp. Bio. 2012, 10, 133-138.

45. Pacini, E.; Nepi, M.; Vesprini, J.L. Nectar biodiversity: A short review. Plant Syst. Evol. 2003, 238, 7-21. [CrossRef]

46. Alqarni, A.S.; Hassan, A.; Owayss, A. Evaluation of Acacia gerrardii benth. (Fabaceae: Mimosoideae) as a honey plant under extremely hot-dry conditions: Flowering phenology, nectar yield and honey potentiality. J. Anim. Plant Sci. 2015, 25, 1667-1674. 